Check for updates

Cite this: RSC Adv., 2020, 10, 10113

Received 13th January 2020

Accepted 27th February 2020

DOI: $10.1039 / \mathrm{dOra00356e}$

rsc.li/rsc-advances

\section{Three-component reaction of azulene, aryl glyoxal and 1,3-dicarbonyl compound for the synthesis of various azulene derivatives $\dagger$}

\author{
Jing Gong, ${ }^{a}$ Anatoly A. Peshkov, ${ }^{b}$ Jiafeng Yu, ${ }^{a}$ Sagadat Amandykova, ${ }^{b}$ \\ Aidana Gimnkhan, ${ }^{b}$ Jianjun Huang, ${ }^{a}$ Stepan Kashtanov, ${ }^{c}$ Olga P. Pereshivko*ab \\ and Vsevolod A. Peshkov (DD *abd
}

A three-component reaction of an azulene, an aryl glyoxal and a 1,3-dicarbonyl compound has been elaborated to access a series of azulene derivatives. Some of these azulene-containing adducts were further subjected to post-MCR transformations to assemble azulene-heterocycle conjugates.

\section{Introduction}

Azulene is a bicyclic aromatic hydrocarbon with a deep blue colour and a dipole moment of about $1.08 \mathrm{D} .{ }^{1}$ Such properties are in striking contrast with those of the isomeric naphthalene that is colourless and has a dipole moment of $0 \mathrm{D}$. The polarity of azulene and in turn the appearance of the blue colour can be explained by the charge-separated resonance structure in which the bicyclic core of azulene is regarded as a fusion of 6 $\pi$-electron cyclopentadienyl anion and $6 \pi$-electron tropylium cation.

Owing to the unique structural and photophysical properties of the azulene core, a number of azulene-based advanced organic materials ${ }^{2}$ has been developed targeting the applications in sensors, ${ }^{3}$ bioimaging, ${ }^{4}$ non-linear optics (NLO) ${ }^{5}$ optoelectronics, ${ }^{6}$ molecular electronics ${ }^{7}$ and so on. Furthermore, azulene derivatives have been successfully incorporated in solar cells $^{8}$ and organic field-effect transistors (OFETs) ${ }^{8 c, d, 9}$ demonstrating high potential for further exploration in this type of devices.

${ }^{a}$ College of Chemistry, Chemical Engineering and Materials Science, Soochow University, Dushu Lake Campus, Suzhou, 215123, P. R. China. E-mail: olga@suda. edu.cn; vsevolod@suda.edu.cn

${ }^{b}$ Department of Chemistry, School of Sciences and Humanities, Nazarbayev University, 53 Kabanbay Batyr Ave, Block 7, Nur-Sultan 010000, Republic of Kazakhstan, . E-mail: olga.pereshivko@nu.edu.kz; vsevolod.peshkov@nu.edu.kz

'Department of Chemistry, Xi'an Jiaotong-Liverpool University, Suzhou, 215123, P. R. China

${ }^{d}$ The Environment and Resource Efficiency Cluster (EREC), Nazarbayev University, Nur-Sultan, Republic of Kazakhstan

$\uparrow$ Electronic supplementary information (ESI) available: Detailed experimental procedures, products characterization, X-ray crystallographic data and copies of UV/vis absorption and NMR spectra. CCDC 1974555. For ESI and crystallographic data in CIF or other electronic format see DOI: 10.1039/d0ra00356e
Consequently, this sparked a growing interest in the development of novel synthetic methodologies for azulene construction $^{\mathbf{1 0}}$ and functionalization ${ }^{\mathbf{1 1}}$ with a special emphasis being given to the assembly of azulene-fused heterocycles, ${ }^{12}$ azulene-heterocycle conjugates ${ }^{\mathbf{1 3}}$ and azulene-containing polymers. ${ }^{\mathbf{8 a}, \boldsymbol{c}, \boldsymbol{d}, \mathbf{1 4}}$

Several recent methodologies for azulene functionalization involve one-pot and/or multicomponent approaches. ${ }^{15}$ On the other hand, in recent years, a number of multicomponent transformations have been developed based on the ability of aryl glyoxals to react with 1,3-dicarbonyl compounds and additional nucleophiles resulting in the formation of structurally diverse (heterocyclic) adducts. ${ }^{16}$ We decided to take an advantage of this strategy towards the synthesis of azulene derivatives through exploration of the nucleophilic potential of the five-membered ring of azulene core.

\section{Results and discussion}

Knowing that the treatment of an aryl glyoxal 2 with a 1,3dicarbonyl compound 3 results in the Knoevenagel condensation, ${ }^{\mathbf{1 6}}$ we envisaged that the presence of an azulene $\mathbf{1}$ would trigger the Michael addition of $\mathbf{1}$ onto the Knoevenagel adduct A. A subsequent proton transfer in the intermediate $\mathbf{B}$ would produce the desired azulene derivative 4 (Scheme 1). After conducting a brief screening of the reaction conditions (see ESI $\dagger$ ), we were pleased to find that such a three-component transformation could be successfully accomplished at the elevated temperature of $80{ }^{\circ} \mathrm{C}$ using isopropanol as a solvent.

The scope of the resulting process is outlined in Scheme 1. In order to evaluate the reactivity of a 1,3-dicarbonyl component 3 , several barbituric acid derivatives and cyclic 1,3-diketones were reacted with unsubstituted azulene and phenyl glyoxal monohydrate resulting in the formation of products $4 \mathbf{a}-\mathbf{f}$ with the yields ranging from $37 \%$ to $91 \%$. Interestingly, according to 


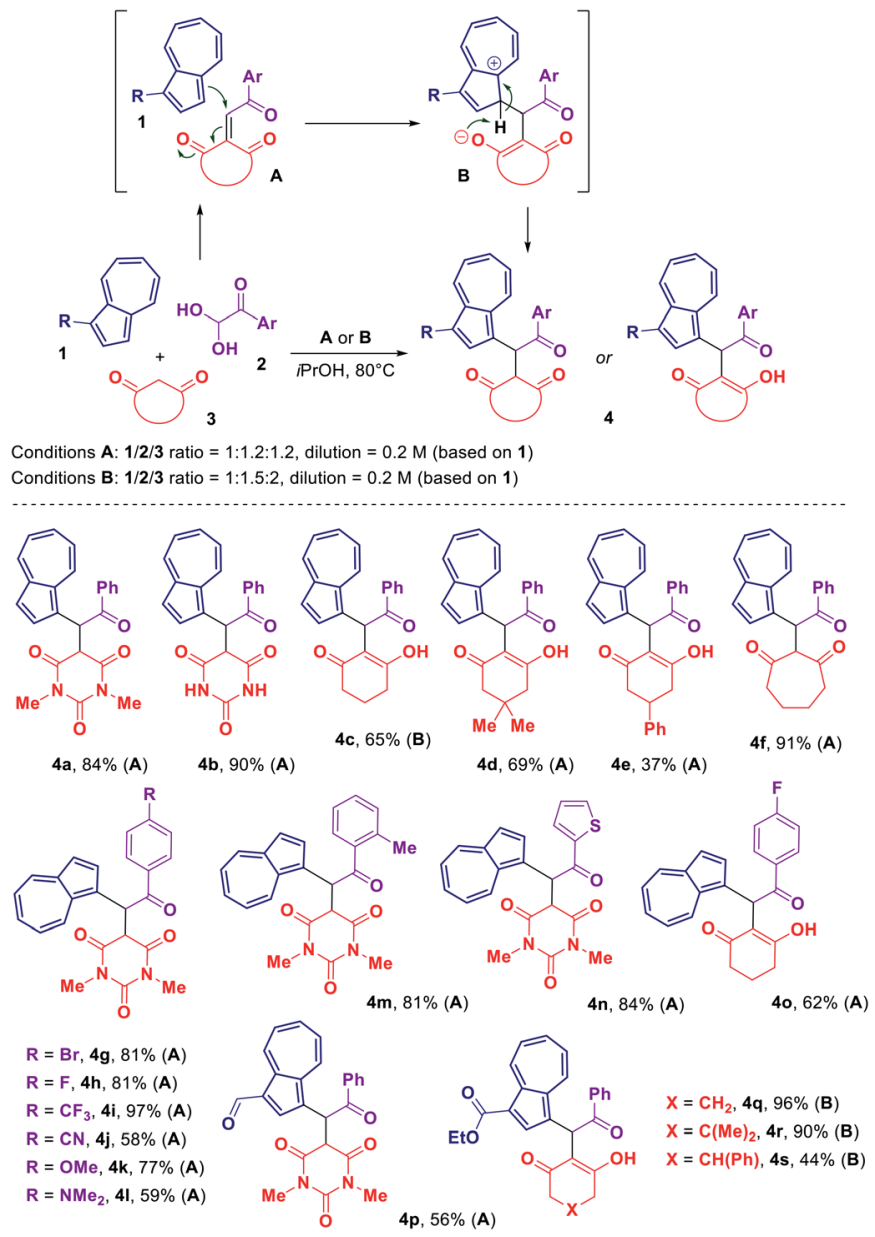

Scheme 1 Scope of the three-component reaction of azulene 1, aryl glyoxal monohydrate 2 and 1,3-dicarbonyl compound 3 .
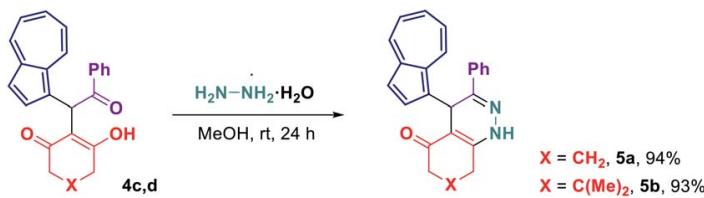

NMR analysis, products $\mathbf{4 a}, \mathbf{b}, \mathbf{f}$ derived from either barbituric acids or cycloheptane-1,3-dione were observed in a keto form in solution $\left(\mathrm{CDCl}_{3}\right.$ for $\mathbf{4 a}$ and $\mathbf{4 f},\left[\mathrm{D}_{6}\right] \mathrm{DMSO}$ for $\left.\mathbf{4 b}\right)$. In contrast, products $\mathbf{4 c - e}$ obtained using various cyclohexane-1,3-diones were observed in a enolized form, with the compound $\mathbf{4 e}$ existing as a mixture of two interconvertible diastereomeric enol forms.

With respect to an aryl glyoxal component 2, a number of variously substituted phenyl glyoxal monohydrates along with a heteroaromatic thiophen-2-yl glyoxal monohydrate have been tested allowing to acquire an array of azulene-containing adducts $\mathbf{4 g}-\mathbf{o}$ (Scheme 1). It was found that the presence of either electron-withdrawing or electron-donating substituent in the phenyl ring of glyoxal could be well tolerated.

Blocking one of the azulene's reactive positions with an electron-withdrawing group did not shut down the reactivity of the azulene core towards our transformation. Thus, we were able to prepare a series of 1,3-disubstituted azulene derivatives 4p-s starting from either azulene-1-carbaldehyde or ethyl azulene-1-carboxylate.

Considering that some of the obtained azulene derivatives, such as for example $\mathbf{4 c}$ and $\mathbf{4 d}$ comprised a 1,4-diketo unit, we decided to probe their reactivity in the condensations with nitrogen nucleophiles towards the formation of azuleneheterocycle conjugates. To our delight, reacting $\mathbf{4 c}$ and $\mathbf{4 d}$ with hydrazine monohydrate in methanol at rt produced azulenetetrahydrocinnoline conjugates $\mathbf{5 a}$ and $\mathbf{5 b}$ in high yields of $94 \%$ and $93 \%$, respectively (Scheme 2). Encouraged by these results, we went on exploring the potential of our 1,4-diketones in a Paal-Knorr synthesis of pyrroles. ${ }^{17}$ Gratifyingly, the treatment of $4 \mathbf{c}, 4 \mathbf{d}$ and $4 \mathbf{o}$ with aniline in isopropanol at $80{ }^{\circ} \mathrm{C}$ allowed to prepare azulene-dihydroindol-4-one conjugates $7 \mathbf{a}-$ c in moderate to good yields (Scheme 3). The molecular structure of representative azulene-dihydroindol-4-one derivative $\mathbf{7 b}$ has been resolved through the X-ray crystallographic analysis (Fig. 1, see ESI $\dagger$ for details). The above synthetic strategy was also found to be amenable to a variation of an amine component 6. Examining different aromatic and

Scheme 2 Synthesis of azulene-tetrahydrocinnolin-5-one conjugates 5.

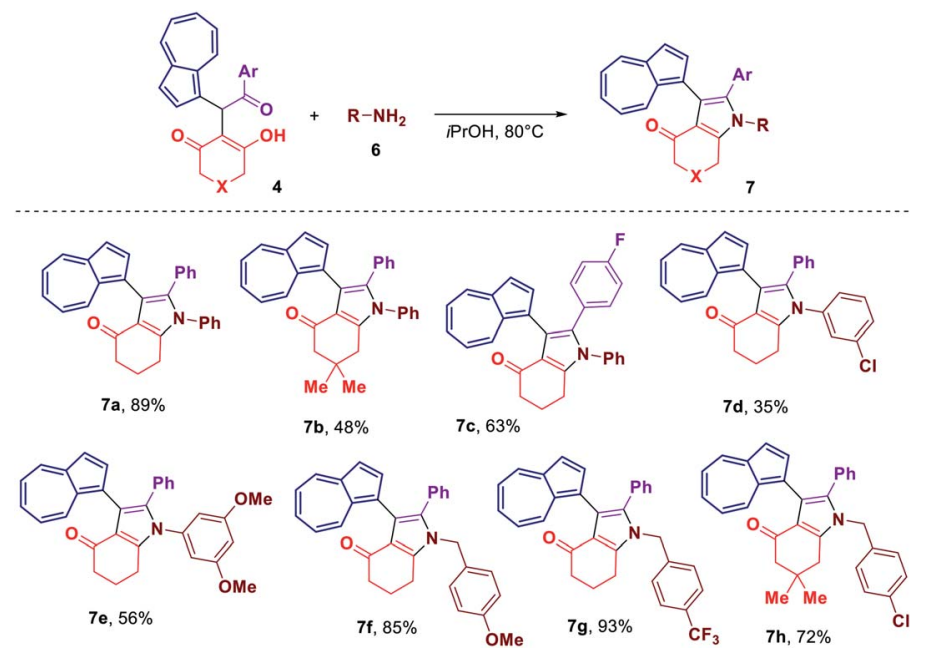

Scheme 3 Synthesis of azulene-dihydroindol-4-one conjugates 7. 


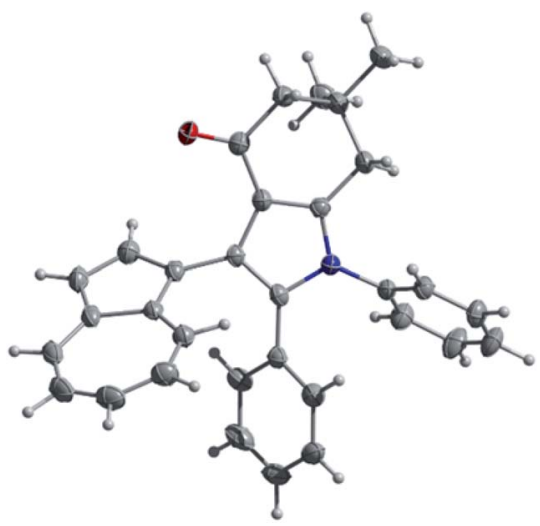

Fig. 1 Molecular structure of $7 \mathrm{~b}$, showing thermal displacement ellipsoids at the $50 \%$ probability level. The dimethyl formamide (DMF) molecule acquired during the crystallization process and present in the crystal packing is not shown.

benzylic amines in the reactions with $\mathbf{4 c}$ or $\mathbf{4 d}$ delivered expected azulene-substituted dihydroindol-4-ones $\mathbf{7} \mathbf{c}-\mathbf{h}$ in up to 93\% yield (Scheme 3 ).

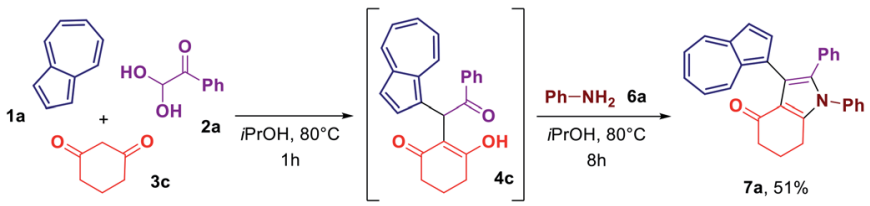

Scheme 4 One-pot synthesis of azulene-dihydroindol-4-one conjugate $7 a$.

In an attempt to streamline the access towards azuleneheterocycle conjugates, we have conducted a one-pot synthesis of compounds 7a (Scheme 4). Reacting azulene (1a), phenyl glyoxal monohydrate (2a) and cyclohexane-1,3-dione (3c) in isopropanol at $80{ }^{\circ} \mathrm{C}$ for $1 \mathrm{~h}$ lead to the formation of acyclic adduct 4c. Once the formation of $\mathbf{4 c}$ was confirmed by the TLC analysis, the aniline (6a) was added and the reaction was continued for another $8 \mathrm{~h}$ allowing to obtain the desired azulene-substituted dihydroindol-4-one $7 \mathrm{a}$ in $51 \%$ overall yield.

The optical properties of all acquired azulene derivatives 4, 5 and 7 have been assessed by measuring their UV/Vis absorption
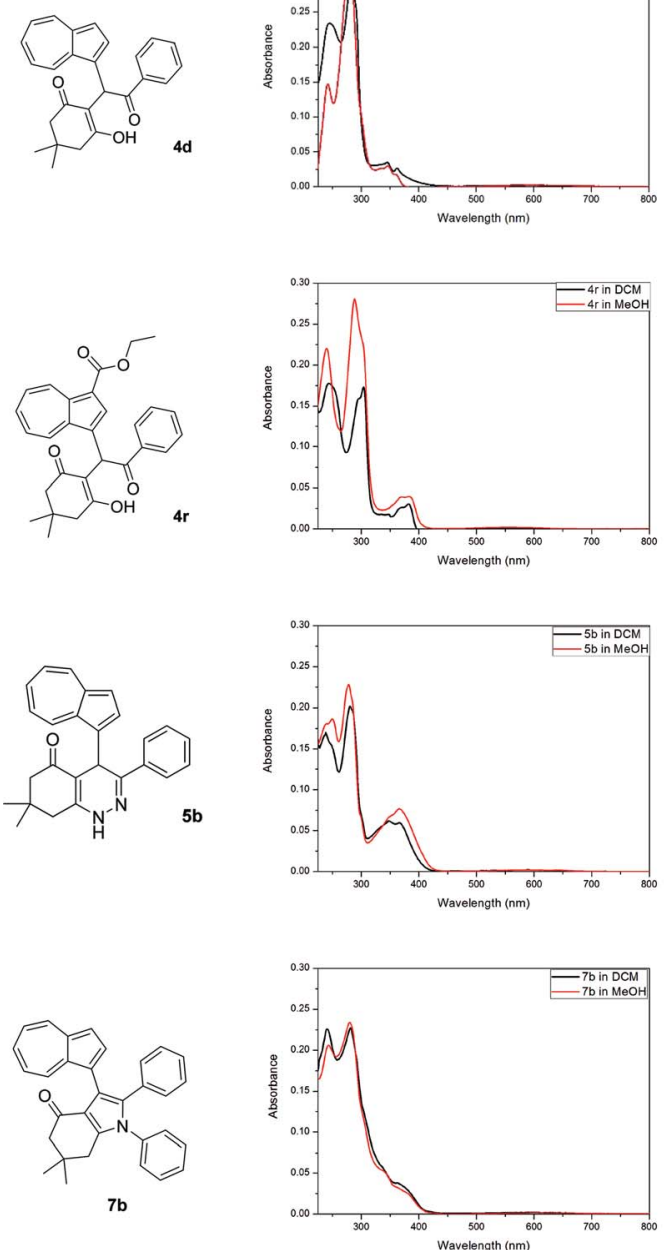
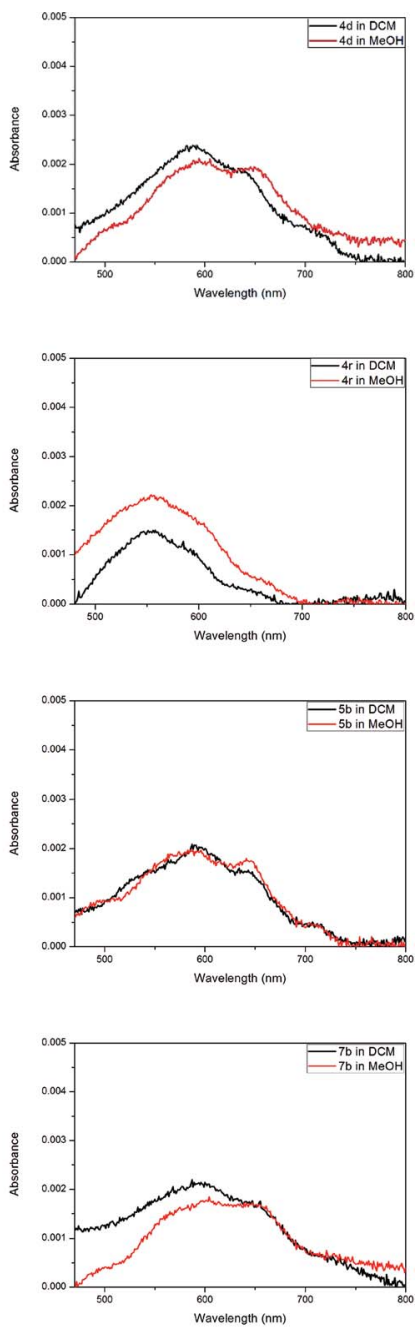

Fig. 2 UV/Vis absorption spectra of $4 \mathrm{~d}, 4 \mathrm{r}, 5 \mathrm{~b}$ and $7 \mathrm{~b}$ measured in dichloromethane and in methanol (both at $c \cong 5 \times 10^{-6} \mathrm{M}$, left column); magnified visible region of UV/Vis absorption spectra of $4 d, 4 r, 5 b$ and $7 b$ (right column). 
in dichloromethane and in methanol (both at $c \cong 5 \times 10^{-6} \mathrm{M}$, see ESI $\dagger)+$ The UV/Vis absorption spectra of representative azulene-containing products $\mathbf{4 d}, \mathbf{4 r}, \mathbf{5 b}$ and $\mathbf{7 b}$ are shown in Fig. 2. Similarly to most of simple azulene derivatives, all prepared compounds 4, 5 and 7 were characterized by a strong absorbance in the UV region and a relatively weak absorbance in the visible region, with the latter being responsible for the colouration of their solutions.

\section{Conclusions}

In conclusion, we have developed a novel multicomponent protocol for the azulene derivatization through the reaction with an aryl glyoxal and a 1,3-dicarbonyl compound. The scope of the process has been briefly explored resulting in generation of a small set of branched azulene-containing adducts. Some of these adducts could be further upgraded into azulene-heterocycle conjugates through the post-MCR condensations with nitrogen nucleophiles. Collectively, these methodologies provide a straightforward access to three distinct types of azulene derivatives.

\section{Conflicts of interest}

There are no conflicts to declare.

\section{Acknowledgements}

This work was supported by the start-up fund from Soochow University (grant Q410900714), National Natural Science Foundation of China (grant 21650110445), Natural Science Foundation of Jiangsu Province of China (grant BK20160310), the Priority Academic Program Development of Jiangsu Higher Education Institutions (PAPD), the Project of Scientific and Technologic Infrastructure of Suzhou (grant SZS201708) and the Social Policy Grant of Nazarbayev University.

\section{Notes and references}

1 (a) D. M. Lemal and G. D. Goldman, J. Chem. Educ., 1988, 65, 923; (b) A. G. Anderson Jr and B. M. Steckler, J. Am. Chem. Soc., 1959, 81, 4941.

2 (a) A. E. Ion, A. Dogaru, S. Shova, A. M. Madalan, O. Akintola, S. Ionescu, M. Voicescu, S. Nica, A. Buchholz, W. Plass and M. Andruh, CrystEngComm, 2018, 20, 4463; (b) F. Wang, T. T. Lin, C. He, H. Chi, T. Tang and Y.-H. Lai, J. Mater. Chem., 2012, 22, 10448; (c) K. Kurotobi, K. S. Kim, S. B. Noh, D. Kim and A. Osuka, Angew. Chem., Int. Ed., 2006, 45, 3944.

3 (a) T. Tang, T. Lin, F. Erden, F. Wang and C. He, J. Mater. Chem. C, 2018, 6, 5153; (b) E. H. Ghazvini Zadeh, A. W. Woodward, D. Richardson, M. V. Bondar and K. D. Belfield, Eur. J. Org. Chem., 2015, 2271; (c) E. Amir, R. J. Amir, L. M. Campos and C. J. Hawker, J. Am. Chem.

\$ UV/Vis absorption of $\mathbf{7 b}$ was measured only in methanol due to poor solubility in dichloromethane.
Soc., 2011, 133, 10046; (d) H. Salman, Y. Abraham, S. Tal, S. Meltzman, M. Kapon, N. Tessler, S. Speiser and Y. Eichen, Eur. J. Org. Chem., 2005, 2207.

4 (a) P. M. Gosavi, Y. S. Moroz and I. V. Korendovych, Chem. Commun., 2015, 51, 5347; (b) Y. S. Moroz, W. Binder, P. Nygren, G. A. Caputod and I. V. Korendovych, Chem. Commun., 2013, 49, 490; (c) W. Pham, R. Weissleder and C.-H. Tung, Angew. Chem., Int. Ed., 2002, 41, 3659; (d) L. C. Murfin, M. Weber, S. J. Park, W. T. Kim, C. M. LopezAlled, C. L. McMullin, F. Pradaux-Caggiano, C. L. Lyall, G. Kociok-Köhn, J. Wenk, S. D. Bull, J. Yoon, H. M. Kim, T. D. James and S. E. Lewis, J. Am. Chem. Soc., 2019, 141, 19389.

5 (a) L. Cristian, I. Sasaki, P. G. Lacroix, B. Donnadieu, I. Asselberghs, K. Clays and A. C. Razus, Chem. Mater., 2004, 16, 3543; (b) P. G. Lacroix, I. Malfant, G. Iftime, A. C. Razus, K. Nakatani and J. A. Delaire, Chem.-Eur. J., 2000, 6, 2599.

6 (a) T. Shoji, K. Miura, T. Araki, A. Maruyama, A. Ohta, R. Sekiguchi, S. Ito and T. Okujima, J. Org. Chem., 2018, 83, 6690; (b) T. Shoji and S. Ito, Chem.-Eur. J., 2017, 23, 16696; (c) H. Xin and X. Gao, ChemPlusChem, 2017, 82, 945; (d) J.-X. Dong and H.-L. Zhang, Chin. Chem. Lett., 2016, 27, 1097. 7 (a) G. Yang, S. Sangtarash, Z. Liu, X. Li, H. Sadeghi, Z. Tan, R. Li, J. Zheng, X. Dong, J. Liu, Y. Yang, J. Shi, Z. Xiao, G. Zhang, C. Lambert, W. Hong and D. Zhang, Chem. Sci., 2017, 8, 7505; (b) F. Schwarz, M. Koch, G. Kastlunger, H. Berke, R. Stadler, K. Venkatesan and E. Lörtscher, Angew. Chem., Int. Ed., 2016, 55, 11781.

8 (a) E. Puodziukynaite, H.-W. Wang, J. Lawrence, A. J. Wise, T. P. Russell, M. D. Barnes and T. Emrick, J. Am. Chem. Soc., 2014, 136, 11043; (b) H. Nishimura, N. Ishida, A. Shimazaki, A. Wakamiya, A. Saeki, L. T. Scott and Y. Murata, J. Am. Chem. Soc., 2015, 137, 15656; (c) J. Yao, Z. Cai, Z. Liu, C. Yu, H. Luo, Y. Yang, S. Yang, G. Zhang and D. Zhang, Macromolecules, 2015, 48, 2039; (d) H. Xin, C. Ge, X. Jiao, X. Yang, K. Rundel, C. R. McNeill and X. Gao, Angew. Chem., Int. Ed., 2018, 57, 1322.

9 (a) E. C. P. Smits, S. Setayesh, T. D. Anthopoulos, M. Buechel, W. Nijssen, R. Coehoorn, P. W. M. Blom, B. de Boer and D. M. de Leeuw, Adv. Mater., 2007, 19, 734; (b) P. H. Wöbkenberg, J. G. Labram, J.-M. Swiecicki, K. Parkhomenko, D. Sredojevic, J.-P. Gisselbrecht, D. M. de Leeuw, D. D. C. Bradley, J.-P. Djukic and T. D. Anthopoulos, J. Mater. Chem., 2010, 20, 3673; (c) Y. Yamaguchi, Y. Maruya, H. Katagiri, K.-i. Nakayama and Y. Ohba, Org. Lett., 2012, 14, 2316; (d) Y. Yamaguchi, K. Ogawa, K.-i. Nakayama, Y. Ohba and H. Katagiri, J. Am. Chem. Soc., 2013, 135, 19095; (e) Y. Yamaguchi, M. Takubo, K. Ogawa, K.-i. Nakayama, T. Koganezawa and H. Katagiri, J. Am. Chem. Soc., 2016, 138, 11335; (f) H. Xin, C. Ge, L. Fu, X. Yang and X. Gao, Chin. J. Org. Chem., 2017, 37, 711; $(g)$ H. Xin, C. Ge, X. Yang, H. Gao, X. Yang and X. Gao, Chem. Sci., 2016, 7, 6701-6705; (h) H. Xin, J. Li, C. Ge, X. Yang, T. Xue and X. Gao, Mater. Chem. Front., 2018, 2, 975.

10 (a) D. D. Nolting, M. Nickels, R. Price, J. C. Gore and W. Pham, Nat. Protoc., 2009, 4, 1113; (b) N. R. Kumar, 
A. R. Agrawal and S. S. Zade, Chem.-Eur. J., 2019, 25, 14064; (c) H. Langhals and M. Eberspächer, Synthesis, 2018, 50, 1862; (d) V. Claus, M. Schukin, S. Harrer, M. Rudolph, F. Rominger, A. M. Asiri, J. Xie and A. S. K. Hashmi, Angew. Chem., Int. Ed., 2018, 57, 12966.

11 (a) M. Fujinaga, K. Suetake, K. Gyoji, T. Murafuji, K. Kurotobi and Y. Sugihara, Synthesis, 2008, 3745; (b) J. Dubovik and A. Bredihhin, Synthesis, 2015, 47, 538; (c) A. Székely, Á. Péter, K. Aradi, G. L. Tolnai and Z. Novák, Org. Lett., 2017, 19, 954; (d) T. Shoji, T. Araki, N. Iida, Y. Kobayashi, A. Ohta, R. Sekiguchi, S. Ito, S. Mori, T. Okujima and M. Yasunami, Eur. J. Org. Chem., 2018, 1145; (e) X. Shi, A. Sasmal, J.-F. Soulé and H. Doucet, Chem.-Asian J., 2018, 13, 143.

12 (a) C. Kogawa, A. Fujiwara, R. Sekiguchi, T. Shoji, J. Kawakami, M. Okazaki and S. Ito, Tetrahedron, 2018, 74, 7018; (b) T. Shoji, T. Araki, N. Iida, K. Miura, A. Ohta, R. Sekiguchi, S. Ito and T. Okujima, Org. Chem. Front., 2019, 6, 195; (c) T. Shoji, K. Miura, A. Ohta, R. Sekiguchi, S. Ito, Y. Endo, T. Nagahata, S. Mori and T. Okujima, Org. Chem. Front., 2019, 6, 2801; (d) H. Xin, J. Li, X. Yang and X. Gao, J. Org. Chem., 2020, 85, 70.

13 (a) A. C. Razus, L. Birzan, A. Corbu, O. Zaharia and C. Enache, ARKIVOC, 2006, (xii), 121; (b) T. Shoji, S. Takagaki, M. Tanaka, T. Araki, S. Sugiyama, R. Sekiguchi, A. Ohta, S. Ito and T. Okujima, Heterocycles, 2017, 94, 1870; (c) T. Shoji, M. Tanaka, S. Takagaki, K. Miura, A. Ohta, R. Sekiguchi, S. Ito, S. Mori and T. Okujima, Org. Biomol. Chem., 2018, 16, 480.
14 (a) F. Wang, Y.-H. Lai and M.-Y. Han, Macromolecules, 2004, 37, 3222; (b) X. Wang, J. K.-P. Ng, P. Jia, T. Lin, C. M. Cho, J. Xu, X. Lu and C. He, Macromolecules, 2009, 42, 5534; (c) K. Tsurui, M. Murai, S.-Y. Ku, C. J. Hawker and M. J. Robb, Adv. Funct. Mater., 2014, 24, 7338.

15 (a) N. Takenaga, K. Fukazawa, M. Maruko and K. Sato, Heterocycles, 2015, 90, 113; (b) C. F. Gers, J. Rosellen, E. Merkul and T. J. J. Müller, Beilstein J. Org. Chem., 2011, 7, 1173.

16 (a) J. Khalafy, M. Rimaz, M. Ezzati and R. H. Prager, Bull. Korean Chem. Soc., 2012, 33, 2890; (b) G.-H. Ma, X.-J. Tu, Y. Ning, B. Jiang and S.-J. Tu, ACS Comb. Sci., 2014, 16, 281; (c) V. A. Peshkov, A. A. Peshkov, O. P. Pereshivko, K. Van Hecke, L. L. Zamigaylo, E. V. Van der Eycken and N. Yu. Gorobets, ACS Comb. Sci., 2014, 16, 535; (d) H. Wei, B. Li, G. Wang, K. Van Hecke, O. P. Pereshivko and V. A. Peshkov, Synthesis, 2016, 48, 1734; (e) X. Yang, L. Zheng, Z. Chen and W. Zhong, Synth. Commun., 2018, 48, 929; (f) X. Chang, X. Zhang and Z. Chen, Org. Biomol. Chem., 2018, 16, 4279; (g) M. Saroha and J. M. Khurana, New J. Chem., 2019, 43, 8644; (h) V. G. Melekhina, V. S. Mityanov, B. V. Lichitsky, A. N. Komogortsev, A. N. Fakhrutdinov, E. D. Daeva and M. M. Krayushkin, Tetrahedron Lett., 2019, 60, 1745; (i) B. V. Lichitsky, A. D. Tretyakov, A. N. Komogortsev, V. S. Mityanov, A. A. Dudinov and M. M. Krayushkin, Chem. Heterocycl. Compd., 2019, 55, 156.

17 A. Balakrishna, A. Aguiara, P. J. M. Sobral, M. Y. Wani, J. Almeida e Silva and A. J. F. N. Sobral, Catal. Rev.: Sci. Eng., 2019, 61, 84. 